greater than that needed to break the chemical bonds. Mechanical fracture of the diamond illustrates the absurdity of opposing chemical to mechanical and electrical factors. Reference is made to some Russian work on the electron theory of chemical affinity and of atom adsorption in crystal lattices. Similar reasoning may be applied in passing from surface adsorption to contact of a film with solid bodies, where the film contains mainly a polymer in solution-as is mostly the case with coating or adhesive films. The active atoms or groups in the film may enter into electronochemical union, accom. panied by transfer of electrons from one phase to the other, obviously leading to formation of the double electric layer.

A possible objection to the new theory is to be found in the query: Why, in adhesive breakdown (delamification), is the double electric layer split up, though having in many cases the nature of a strong chemical bond, while there is little or no cohesive break along a line, probably of less or even of least resistance? Deryagin's reply is not very clear. $\mathrm{He}_{\Theta}$ thinks that the principle or rule under which break. down should occur along a line of least resistance is ambiguous and generally futile until a satisfactory measure of resistance is agreed. This line may vary, for example, with changes in speed of load application. If we consider splitting along a surface, in stages, and the measure of resistance is taken to be the specific work expended in tear-off, the principle of least resistance completely loses validity. This is discussed somewhat vaguely by Deryagin, and at length, including non-adhesive examples. In any event, it appears necessary to develop the theory somewhat further to permit combination of charge density in the double layer with the nature of func. tional groups in the adhesive, the presence there of active atoms and radicals, and the interaction between these structural elements of the adhesive and the surfaces to be joined.

Another approach to the problem of the origin of the electrical double layer, though possibly more limited, is to be found in studying the contact of a polymer film with metal. This is considered in connexion with electron transfer with the production of electron gas in the metal. In a vacuum such a transfer is only possible at high temperatures, such as those of thermo-emission or photo-effect. The formation and diffusion of the electron cloud and its results are also considered.

Referring to work in the United States by Skinner and colleagues ${ }^{s}$, Deryagin considers that their theory of formation of an electrical double layer contains quite a few errors "and is probably only of qualitative interest" ; Skinner et. al do not cite any of the Soviet work on this electrical theory of adhesion, and he claims that they have ignored the fundamental difference between simultaneous and gradual disturbance or fracture of contact over the whole area. 'There is no doubt, he continues, that the research already begun on the nature of film adhesion merits wider development, especially if this includes the really practical evaluation of adhesives in different fields of Soviet economy. It is very important to establish closer contact with workers in manufacturing industry directly engæged on new adhesive formulations and uses, and also those particularly interested in building up a sound scientific theory of adhesion.

Of special interest here is the so-called autoconglomeration or self-adhesion (using terminology suggested by I. I. Zhukov) as observed in bringing into contact two identical strips of polymer, such as rubber. Experiment shows that the work of separating such double-folded strips increases not only with the speed of tear-off, but also with the duration of previous contact and amount of pressure. Such auto-adhesion, of course, is greatly affected by temperature conditions. All these various relations, including that between the structure of the polymer chains and their length, have been studied by different workers-for example, Voyutskii, Krotova, Deryagin and others--who have suggested that the phenomena of self-adhesion to a large extent are determined by intra-molecular thermal movement, forming the basis of polymer elasticity and leading, with contact of two polymer surfaces, to mutual interweaving and diffusion of their chains.

Thus, the surface of separation initially retained on bringing into contact two homogeneous polymers gradually disappears, and instead of two layers of polymer only one exists. Separation or tear now proceeds elsewhere, and the work involved is typical of the cohesion of the material. It is difficult to separate the macroscopic process, of gradual increase of true surface of contact of two materials, from the molecular mechanism of diffusion and interlocking of polymer chains. The initially true area of molecular contact will be considerably less than the apparently nominal. But gradually, owing to flow and relaxation of the polymer, the true area of contact will increase - with a tendency to approach the nominal. Since relaxation and plastic flow in polymers in turn are connected with deformation of macromolecular chains, it is difficult strictly to separate the two mechanisms-molecular coalescence and plastic flow in the contact zones. Further experimental research is necessary, including study of other fields of adhesion phenomena which, in the course of this review, cannot be considered here.

W. G. CASS

1 Adhesives and Resins (Jan. and March, 1955).

"Rev. Produits Chim., 57, 469 (1954); 58, 70 (1955).

Kunstatoffe, 44 (9), 385 (1954).

${ }^{4}$ Vestnik. An S.S.S.R., 7 (1954). Summarized also in Research (Feb. 1955).

s J. App. Phys. (Мау, 1953).

\section{JOINT ESTABLISHMENT FOR NUCLEAR ENERGY RESEARCH} REPORT FOR 1953-54

$\mathrm{T}$ HE third annual report of the Joint Establish. ment for Nuclear Energy Research, which has recently been issued*, contains details of the activities of the Establishment during the year ending June 30, 1954. The Establishment, which is located at Kjeller in Norway, is operated jointly by The Netherlands and Norway and is directed by Mr. Gunnar Rardars. The experimental equipment includes a $300-\mathrm{kW}$. heavy-water-moderated, natural-uranium reactor, Joint Establishment Experimental Pile (JEEP), which has been in continuous operation during the year, though four of the uranium rods were found to be defective and had to be replaced. An additional rod, bringing the total up to sixty-five, was required in order to compensate for the heavier load of isotopes. New equipment installed during the year included a pneumatic arrangement for removing isotopes quickly from the reactor and a mechanical

* Joint Establishment for Nuclear Energy Research. Third Annual Report, 1953-54. Pp. Pii +28. (K Jeller, near Lillestrom : Joint Estab-
lishment for Nuclear Fuergy Research, 1955.) 
master-slave manipulator for remote handling of radioactive material.

The design of an experimental power reactor in which heavy water and natural uranium are to be used in a pressurized system has continued. The general planning has.now reached an advanced stage, and recent work has been concentrated on the design of the natural-uranium fuel elements. The reactor is to be contained within a cylindrical pressurized stainless-steel tank, and the cooling circuit for the fuel elements, which is separated from the moderator, will provide hot heavy-water which will be used for steam production in a boiler connected to a conventional type of turbogenerator.

In November 1953 an extension to the building housing the pile was completed, and the physics, isotope and electronics laboratories and the offices for the Operations and Engineering Department are now housed together in this building. In June 1954 work was started on a new laboratory and workshop building to house the metallurgy and engineering groups and the Reactor Physics Department.

Work in the Chemistry Department has been divided between service tasks for other departments and the study on a laboratory scale of the chemistry of uranium and plutonium, particularly in order to design a pilot plant capable of dissolving up to ten tons of burned uranium rods a year, including the separation of plutonium and the reprocessing of the uranium metal. A 'hot' uranium slug was dissolved in concentrated nitric acid in an all-glass apparatus, the experiment being carried out by remote control behind a $40-\mathrm{cm}$. thick water wall. The solution obtained contained about $10 \mathrm{mgm}$. of plutonium. Arrangements have been made for the production of uranium metal by the reduction of uranium tetrafluoride with calcium. The uranium tetrafluoride was produced in accordance with the French method, that is, by reduction and fluorination of uranium tetraoxide, and the report states that uranium of a fair degree of purity has been obtained. Although the metallurgical laboratory is still under construction, some of the metallographic equipment has arrived, and studies of the de-gassing of uranium at elevated temperatures have been undertaken. The stabilization and canning of the uranium and the diffusion of uranium and aluminium at $200^{\circ} \mathrm{C}$. and higher temperatures are other problems which have engaged the attention of the metallurgical group.

The production of isotopes has greatly increased, and the number of radioisotope shipments, namely, 335 , is more than double that for $1952-53 ; 65$ per cent of these shipments were for export. The different types of isotopes produced and the number of irradiations made in the several departments of the Establishment, together with the number of shipments, their destinations and main fields of application, are listed in the annual report. Stocks of radiocobalt and of radioiridium with fairly high specific activity suitable for industrial radiography have been developed, and many special isotope preparations of medical interest are, or will shortly become, available. No increase in the number of isotopes imported for distribution in Norway is reported. Eighty-four shipments were received from Great Britain, one from the United States and one from Canada. Three examples to illustrate the different technical applications of radioactive isotopes carried out by the Isotope Department during the year are described in some detail in the report. They are concerned with the transport of materials in rotary cement kilns, the loss of catalyst material in the industrial production of nitric acid, and the wear of ball bearings.

The sections of the report devoted to the activities of the Neutron Physics and Reactor Physics Departments are particularly interesting. The fission crosssection of uranium-235, the crystal structure of copper hydride and the magnetic structure of magnetite have been studied by the Neutron Physics Department. The principle of operation of the simple mechanical monochromator for neutrons used at the Establishment, the results of measurements of the rate of fission cross-section of uranium-235 and $(n, \alpha)$ cross-section of boron as a function of neutron energy, and the neutron diffractometer used for crystal structure analysis are some of the topics discussed in the report. The critical factors of various reactor designs were studied by the Reactor Physics Group; other problems considered were shielding properties of concrete, the effect of prompt and delayed $\gamma$-emission on the reactivity of the Pile and the rate of plutonium production in heavy-water reactors.

The report concludes with a list of the Establishment's reports and publications issued during the year, details of the staff of the various departments, and an abstract of the financial accounts for the period under review.

\section{THE PHYSICAL SOCIETY REPORT FOR 1954}

$T$ HE report of the Council of the Physical Society for the year ending December 31, 1954, together with the report of the honorary treasurer and the annual accounts and balance sheet, were presented to the annual meeting of the Society held at the Royal Institution, London, on May 11, and adopted. Immediately following the annual meeting, Prof. H. S. W. Massey delivered his presidential address, entitled "Progress and Problems of Physics To-day", in which he described a selection of remarkable achievements in recent research in physics which illustrate the very advanced state of technique to-day, and then dealt with some of the problems, for example, the growing shortage of science teachers in schools and the tendency to extreme specialization, which the great expansion of research in physics has raised. The text of his address will be published in the separate issue of the Proceedings of the Society to be called the "Proceedings of the Physical Society Yearbook". The "Yearbook" will also contain the texts of the 1955 Guthrie Lecture and the Thomas Young Oration.

The report states that during the year the student membership of the Society decreased by approximately a quarter to 279 , and the total membership fell to 2,046 with a net decrease of eighty-four. There was a small balance of income over expenditure; but the financial position at the end of 1954 was markedly less favourable than at the end of 1953 , the deterioration being attributed, in particular, to $a$ decrease in the income from the annual exhibition of scientific instruments and to the absence, in 1954, of a grant-in-aid in respect of the Society's publications. It is true that the cost of the Society's publications, including its commitment in respect of Science Abstracts, was almost balanced by the income from 